\title{
The Effect of Weather Conditions on Pediatric Supracondylar Humerus Fractures
}

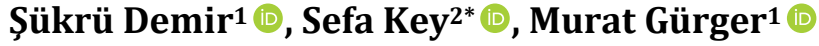 \\ ${ }^{1}$ Department of Orthopedics, Firat University Hospital, Firat University, Elazig, Turkey \\ ${ }^{2}$ Department of Orthopedics, Bingol State Hospital, Ministry of Health, Bingol, Turkey \\ Email: drsukrudemir@yahoo.com, *sefa_key@hotmail.com, muratgurger@hotmail.com
}

How to cite this paper: Demir, S., Key, S. and Gürger, M. (2021) The Effect of Weather Conditions on Pediatric Supracondylar Humerus Fractures. Open Journal of Orthopedics, 11, 308-314.

https://doi.org/10.4236/ojo.2021.1110029

Received: August 20, 2021

Accepted: October 19, 2021

Published: October 22, 2021

Copyright $\odot 2021$ by author(s) and Scientific Research Publishing Inc. This work is licensed under the Creative Commons Attribution International License (CC BY 4.0).

http://creativecommons.org/licenses/by/4.0/

\begin{abstract}
Background: Environmental conditions are effective on childhood supracondylar humerus fractures. In this study, we evaluated the relationship between weather conditions and these fractures. Materials and Methods: We started this study following the approval of a non-interventional research ethics committee. Patients ( $<16$ years) who applied to the hospital between January 2013 and July 2018 with supracondylar humerus fractures were included in the study. The hospital's PROBEL system was used to diagnose (International Classification of the Diseases, ICD, S42.4) radiological images and patient information. Information on the weather conditions in the day and time period, in which supracondylar humerus fracture occurred, was obtained from TR (Turkey) Ministry of Agriculture and Forestry General Directorate of Meteorology. The relationship between supracondylar fracture and daily weather conditions (wind, air temperature, cloudiness, and season) was analyzed. Results: Most of the patients ( $\mathrm{n}=76,40.6 \%, \mathrm{p}<0.05)$ were fractures occurring under cloudless weather conditions. Fractures were concentrated with a second frequency in cloudy weather over $60 \%$, except for cloudless weather conditions (n $=51,27.3 \%, \mathrm{p}<0.05)$. In the summer months when the air temperature was high, the number of fractures was higher $(\mathrm{n}=62,33.2 \%, \mathrm{p}<0.05)$ and less in the winter months $(\mathrm{n}=24,12.8 \%, \mathrm{p}<0.05)$. In hot weather conditions where the daily average temperature was above $20^{\circ} \mathrm{C}$, supracondylar humerus fractures were observed more $(\mathrm{n}=101,54 \%)$ and less than $10^{\circ} \mathrm{C}(\mathrm{n}=43,23 \%, \mathrm{p}$ $<0.05)$. Increased incidence of fractures was observed in the presence of wind $(\mathrm{n}=4,2.1 \%, \mathrm{p}<0.05)$. Conclusion: Supracondylar humerus fractures are common in children. Environmental conditions (temperature, wind, and season) can be effective in the occurrence of these fractures.
\end{abstract}

\section{Keywords}

Supracondylar Humerus Fracture, Seasonal Change, Weather Conditions, 


\section{Introduction}

Supracondylar humerus fractures are the most common causes of childhood elbow injuries. Complicated structure and distinctive radiological anatomy of the elbow joint in this period concern surgeons [1]. The average age at admission is between 3 and 8 years old. The most common mechanism of the injury is the extension-type supracondylar humerus fracture, which is caused by a fall on an outstretched hand with wrist and elbow extension [2]. A fall on a flexed elbow leads to flexion-type supracondylar humerus fracture, though it is observed less frequently. There are many factors that affect the development of fractures in children. Genetic features, nutrition, vitamin deficiencies and environmental factors can affect fracture formation. Conditions such as low socioeconomic status, exposure to cigarettes, carbonated drinks and high-carbohydrate foods can affect fracture formation in children [3].

In a child with an elbow injury, a radiological evaluation is required for the diagnosis of supracondylar humerus fracture. In radiological evaluation, the elbow should include two radiographs, AP and side. In the lateral elbow X-ray, the fact that the anterior humerus line does not pass through the capitellum center supports the diagnosis. Imaging and a good physical examination are required for an accurate diagnosis. Significant edema and deformation of the elbow on physical examination strengthen the diagnosis of supracondylar humerus fracture. Neurovascular evaluation is also important in these fractures [4]. To show the reasons for the occurrence of supracondylar fractures, which are frequently seen in children and may result in serious disability, the relationship between weather and fracture was examined.

There are several factors involved in fracture development in children. Environmental factors are also important. Environmental conditions such as low socioeconomic level, smoking, nutritional status and weather conditions have been associated with fracture development [5]. Even though the association between weather conditions and pediatric fractures is controversial, pediatric forearm fractures have been reported to occur more in dry and hot days [6]. The present study aims to examine the effect of changes in weather conditions, such as the season, air temperature, wind, cloudiness and rainfall, on pediatric supracondylar humerus fractures.

\section{Methods}

The main objective of this work is to show relationship pediatric supracondylar humerus fractures and the weather condition. The study was approved by the Non-Interventional Trials Ethics Committee. Included in the study were all patients under 16 years of age, who presented with supracondylar humerus fracture, and treated as inpatients or outpatients between January 2013 and July 2018. The 
Gartland classification (Type 2, Type 3, and Type 3F (Flexion)) of supracondylar humerus fractures was used for all patients [7]. The used all fractures occurred outside. For each patient, an analysis was made into the association between supracondylar humerus fracture and meteorological data (air temperature, cloudiness, wind) of the season and time period when the fracture developed. The meteorological data were retrieved from TR (Turkey) Ministry of Agriculture and Forestry General Directorate of Meteorology. Upon reviewing the hospital PACS system and the ICD, S42.4 diagnosis code, radiological images, and patient details of a total of 187 patients were accessed. From the meteorological data, the daily maximum temperature was grouped into $>20^{\circ} \mathrm{C}$ hot, $10^{\circ} \mathrm{C}-20^{\circ} \mathrm{C}$ warm, and $<10^{\circ} \mathrm{C}$ cold, and the cloudiness rate into $<40 \%, 40 \%-60 \%$, and $>60 \%$. The wind was analyzed as the average wind direction (according to points of the compass) and the presence of wind at a height of $10-12 \mathrm{~m}$ above the ground during the day.

\section{Statistical Analyses}

SPSS version 22.0 software was used for statistical analysis. Categorical variables were expressed as frequency and percentage, while continuous variables were presented as mean \pm SD. A $p$ value of $<0.05$ was considered statistically significant. The calculated $\mathrm{p}$ value was 0.0024 .

\section{Results}

A total of 187 supracondylar humerus fractures were included in the study with $120(64.2 \%)$ being on the left and $67(35.8 \%)$ on the right side. Based on the classification of supracondylar humerus fractures, 56 (29.9\%) patients had Type 2, 123 (65.8\%) patients had Type 3, and 8 (4.3\%) patients had Type 3F fracture (Table $1)$.

A seasonal analysis revealed that the incidence of supracondylar humerus fracture was higher in the hot summer months $(\mathrm{n}=62,33.2 \%)$ than in the winter months $(\mathrm{n}=24,12.8 \%)$ (Table 2).

When the association between air temperatures and fractures was examined, the supracondylar humerus fractures were found to be more common $(\mathrm{n}=101$, $54 \%$ ) when it was hot, i.e. above $20^{\circ} \mathrm{C}$. Accordingly, the lowest fracture incidence $(\mathrm{n}=43,23 \%)$ was at temperatures below $10^{\circ} \mathrm{C}$. The remaining $43(23 \%)$ patients had fractures when it was $10^{\circ} \mathrm{C}-20^{\circ} \mathrm{C}$ (Table 2).

An analysis of the association between supracondylar humerus fractures and the cloudiness rate indicated that a great majority of the fractures $(n=76,40.6 \%)$ occurred in cloudless weather, followed by the fractures occurring when the cloudiness rate was above $60 \%(\mathrm{n}=51,27.3 \%)$. Seventeen $(9.1 \%)$ and $43(23.0 \%)$ fractures occurred when the cloudiness rate was below $40 \%$, and between $40 \%$ $60 \%$, respectively (Table 2 ).

The incidence of fracture was observed to be very low on windless days $(\mathrm{n}=$ $2,1.1 \%)$ and to increase in the presence of wind. There were more fractures on days with a westerly-northwesterly and easterly wind (Table 2). 
Table 1. Distribution of supracondylar humerus fractures by directions.

\begin{tabular}{|c|c|c|}
\hline \multicolumn{2}{|c|}{ Clinical Features } & \multirow{2}{*}{$\begin{array}{c}\text { Frequency (\%) } \\
67(35.8)\end{array}$} \\
\hline \multirow{3}{*}{ Direction } & Right & \\
\hline & Left & $120(64.2)$ \\
\hline & Total & $187(100)$ \\
\hline \multirow{4}{*}{ Fracture Type } & 2 & $56(29.9)$ \\
\hline & 3 & $123(65.8)$ \\
\hline & $3(F)$ & $8(4.3)$ \\
\hline & Total & $187(100)$ \\
\hline
\end{tabular}

Table 2. Distribution of supracondylar humerus fractures according to meteorological conditions.

\begin{tabular}{|c|c|c|}
\hline \multicolumn{2}{|c|}{ Meteorological Features } & \multirow{2}{*}{$\begin{array}{c}\text { Frequency (\%) } \\
76(40.6)\end{array}$} \\
\hline \multirow{5}{*}{ Cloud Status } & Cloudless & \\
\hline & $<40 \%$ & $17(9.1)$ \\
\hline & $40 \%-60 \%$ & $43(23.0)$ \\
\hline & $>60 \%$ & $51(27.3)$ \\
\hline & Total & $187(100)$ \\
\hline \multirow{5}{*}{ Season } & Spring & $53(28.3)$ \\
\hline & Summer & $62(33.2)$ \\
\hline & Autumn & $48(25.7)$ \\
\hline & Winter & $24(12.8)$ \\
\hline & Total & $187(100)$ \\
\hline \multirow{4}{*}{ Temperature } & $<10^{\circ} \mathrm{C}$ & $43(23.0 \%)$ \\
\hline & $10^{\circ} \mathrm{C}-20^{\circ} \mathrm{C}$ & $43(23.0)$ \\
\hline & $>20^{\circ} \mathrm{C}$ & $101(54.0)$ \\
\hline & Total & $187(100)$ \\
\hline \multirow{12}{*}{ Wind Direction } & West-Southwest & $20(10.7)$ \\
\hline & West-Northwest & $26(13.9)$ \\
\hline & West & $23(12.3)$ \\
\hline & East-Southeast & $4(2.1)$ \\
\hline & East-Northeast & $17(9.1)$ \\
\hline & East & $26(13.9)$ \\
\hline & South-Southwest & $8(4.3)$ \\
\hline & South-Southeast & $3(1.6)$ \\
\hline & Southwest & $15(8.0)$ \\
\hline & South & $10(5.3)$ \\
\hline & Southeast & $1(0.5)$ \\
\hline & North-Northwest & $5(2.7)$ \\
\hline
\end{tabular}




\begin{tabular}{cc}
\hline North-Northeast & $2(1.1)$ \\
Northwest & $19(10.2)$ \\
North & $4(2.1)$ \\
Northeast & $2(1.1)$ \\
Windless Calm & $2(1.1)$ \\
Total & $187(100)$ \\
\hline
\end{tabular}

\section{Discussions and Conclusions}

Supracondylar humerus fractures are important and common pediatric fractures [8]. It can cause morbidity in the long term, despite all treatments [9] with morbidity being higher especially in flexion-type fractures. Surgical intervention is gaining popularity as a treatment [10], which makes it more important to prevent such fractures. Ho et al. established that the distal radius fractures among children occurred more during their playtime in the summer and spring months [11]. Injuries may increase when weather conditions are suitable for spending time outside. Weather conditions have been reported to affect the risk of injury and fractures in children rather than adults [12]. A previous study from Finland established more distal radius fractures among old women in the winter months due to slippery sidewalks [13].

The present study found supracondylar humerus fractures to be more common in summer. When the association between air temperatures and fractures was examined, the supracondylar humerus fractures were found to be more common when it was hot, i.e. above $20^{\circ} \mathrm{C}$. The risk of injury and fracture might have been reduced due to the tendency of children to stay at home more in cold days. There may be increased activity during time outside in hot days. The activities children engage in during their time outside may vary depending on cultural characteristics. Furthermore, children's outdoor activities may also differ during school term and summer break. Such variabilities may also have an effect on the association between supracondylar humerus fractures and weather conditions. That is to say, the present study observed an increased incidence of fracture in the presence of wind as well as an increased fracture frequency on cloudless days and at a cloud density above $60 \%$. Such environmental risk factors as season, air temperature, and wind were found to be associated with the occurrence of fractures. On the other hand, Sinikumpu et al. reported that rainfall and wind were not risk factors for humerus fractures and the findings did not vary between school term and summer break [6]. Segal et al., in turn, examined all pediatric fractures presenting at emergency departments, and reported that the fractures had a bimodal distribution and the rates were similar in summer and winter seasons. The authors found hot weather to be correlated with low fracture risk. They also established that pediatric fractures occurred more during the school term when compared to the summer break [14]. 
The present study determined an association between supracondylar humerus fractures and such outdoor weather conditions as wind, air temperature, and cloudiness, which are among environmental risk factors, and demonstrated that weather conditions might affect the fracture incidence.

The limitation of this works is to use a small data, since we collected these data from one medical center.

In conclusion, to reduce the number of such fractures, it is important to understand and manage the risk factors associated with supracondylar humerus fractures, which are common in children and may result in morbidity. The data of patients, who were diagnosed and followed-up by a single-center, were assessed at the same center, which is the strength of the present study. The meteorological data were also obtained from a single center. However, the patient population represents a limited region. Accordingly, studies involving patients from larger regions may be needed to analyze the association between weather conditions and pediatric supracondylar humerus fractures. Factors such as socioeconomic level, education, and weather are effective in the occurrence of fractures in children, but perhaps one of the most important factors is the closure of schools and the holiday time for children. Therefore, it will be useful to investigate other possible factors on the occurrence of supracondylar humerus fractures. The weather conditions can be effective in the occurrence of pediatric supracondylar fractures. However, this is one of the factors which cannot be modified. Since the pediatric supracondylar fractures arising from high energy and treated by surgically are more common in the cloudless and hot weather conditions, pediatric orthopedic clinics should prepare themselves for these type injuries on summer days. The risk of injury and fracture might have been reduced due to the tendency of children to stay at home more in cold days. There may be increased activity during time outside in hot days. Fracture risk in children is indirectly related to the activity. Seasonal features are one of the effective factors on pediatric fractures. The frequency of these injuries may increase as the time spent outdoors increases in hot and clear weather.

\section{Conflicts of Interest}

Şükrü Demir, Sefa Key, Murat Gürger and Gokhan Once declare that they have no conflict of interest.

\section{References}

[1] Mitchelson, A.J., Illingworth, K.D., Robinson, B.S., et al. (2013) Patient Demographics and Risk Factors in Pediatric Distal Humeral Supracondylar Fractures. Orthopedics, 36, e700-e706. https://doi.org/10.3928/01477447-20130523-12

[2] Skaggs, D.L. and Frick, S.L. (2014) Upper Extremity Fractures in Children. Lovell and Winter's Pediatric Orthopaedics. In: Weinstein, S., Skaggs, D. and Flynn, J., Eds., Lovell and Winter's Pediatric Orthopaedics, Lippincott Williams \& Wilkins, Philadelphia.

[3] Goulding, A. (2007) Childhood Fractures: Time to Implement Strategies to Reduce 
These Events. International Congress Series, 1297, 3-14. https://doi.org/10.1016/j.ics.2006.08.022

[4] Shah, A.S., Waters, P.M. and Bae, D.S. (2013) Treatment of the "Pink Pulseless Hand" in Pediatric Supracondylar Humerus Fractures. Journal of Hand Surgery, 38, 13991403. https://doi.org/10.1016/j.jhsa.2013.03.047

[5] Goulding, A. (2007) Risk Factors for Fractures in Normally Active Children and Adolescents. Medicine and Sport Science, 51, 102-120. https://doi.org/10.1159/000103007

[6] Sinikumpu, J.-J., Pokka, T., Sirniö, K., Ruuhela, R. and Serlo, W. (2013) PopulationBased Research on the Relationship between Summer Weather and Paediatric Forearm Shaft Fractures. Injury, 44, 1569-1573. https://doi.org/10.1016/j.injury.2013.04.021

[7] Alton, T.B., Werner, S.E. and Gee, A.O. (2015) Classifications in Brief: The Gartland Classification of Supracondylar Humerus Fractures. Clinical Orthopaedics and Related Research, 473, 738-741. https://doi.org/10.1007/s11999-014-4033-8

[8] Howard, A., Mulpuri, K., Abel, M.F., et al. (2012) The Treatment of Pediatric Supracondylar Humerus Fractures. Journal of the American Academy of Orthopaedic Surgeons, 20, 320-327. https://doi.org/10.5435/JAAOS-20-05-320

[9] Sinikumpu, J., Victorzon, S., Pokka, T., Lindholm, E., Peljo, T. and Serlo, W. (2016) The Long-Term Outcome of Childhood Supracondylar Humeral Fractures: A Population-Based Follow up Study with a Minimum Follow up of Ten Years and Normal Matched Comparisons. The Bone \& Joint Journal, 98, 1410-1417.

https://doi.org/10.1302/0301-620X.98B10.35923

[10] Salonen, A., Pajulo, O., Lahdes-Vasama, T., Välipakka, J. and Mattila, V. (2013) Increased Incidence of Distal Humeral Fractures and Surgical Treatment in 0- to 18-YearOld Patients Treated in Finland from 1987 to 2010. Journal of Children's Orthopaedics, 7, 559-564. https://doi.org/10.1007/s11832-013-0529-0

[11] Ho, V.P., Towe, C.W., Chan, J. and Barie, P.S. (2015) How's the Weather? Relationship between Weather and Trauma Admissions at a Level I Trauma Center. World Journal of Surgery, 39, 934-939. https://doi.org/10.1007/s00268-014-2881-8

[12] Flinkkilä, T., Sirniö, K., Hippi, M., et al. (2011) Epidemiology and Seasonal Variation of Distal Radius Fractures in Oulu, Finland. Osteoporosis International, 22, 2307-2312. https://doi.org/10.1007/s00198-010-1463-3

[13] Sinikumpu, J.-J., Pokka, T., Hyvönen, H., Ruuhela, R. and Serlo, W. (2017) Supracondylar Humerus Fractures in Children: The Effect of Weather Conditions on Their Risk. European Journal of Orthopaedic Surgery \& Traumatology, 27, 243-250. https://doi.org/10.1007/s00590-016-1890-8

[14] Segal, D., Slevin, O., Aliev, E., et al. (2018) Trends in the Seasonal Variation of Paediatric Fractures. Journal of Children's Orthopaedics, 12, 614-621.

https://doi.org/10.1302/1863-2548.12.180114 